\title{
Identidad digital de los adolescentes: la narrativa del yo
}

\author{
Digital identity in adolescents: the narrative of the self
}

\author{
Isabel Dans
}

Universidade da Coruña

\begin{abstract}
Resumen
La presente comunicación se plantea como objetivo la exposición de las teorías sobre la identidad para abordar, en concreto, la identidad entre adolescentes en relación al mundo digital. El juego identitario como elección del usuario y la formación de estereotipos a través de los perfiles digitales es un fenómeno emergente, que requiere de atención educativa. A raíz de la inclusión en un grupo o red se plantea la realidad digital como conexión entre lo público, lo privado y lo íntimo a través del recorrido por las nociones de intimidad, privacidad, autenticidad, solidaridad y compromiso, contactos y amistad.

Palabras clave: identidad digital, adolescencia, personalidad.

\section{Abstract}

This communication therefore seeks an exposition of theories of identity, to address, namely, identity among adolescents in relation to the digital world. The identity game as user choice and formation of stereotypes through digital profiles is an emergent phenomenon, requiring educational care. the media constantly warn of the risks in social networks, but it seems necessary to describe the fingerprint in adolescence as a fact without fear, to work together to increase the benefits it brings. Following its inclusion in a group or network, he considers digital reality as a connection between the public, private and intimate through the notions of intimacy, privacy, authenticity, solidarity and commitment, contacts and friends.

Keywords:adolescence, digital identity, personality.
\end{abstract}

\section{Concepto de identidad}

La visión del conjunto sobre la identidad puede referirse a lo biológico, en la dimensión corporal de la persona; la identidad psicológica, entendida ésta por dónde se sitúa en sí mismo el individuo en cuanto “yo”; o la identidad sociológica, cada uno respecto al conjunto, es decir, inserto en una sociedad, en un grupo, etc. Otro concepto que utilizan los filósofos personalistas es el de identidad narrativa. Esta consistiría en tratar a la persona y estudiarla como protagonista de una historia o un relato, que ella misma narra en su propia red. Para tratar la identidad personal, hemos de abordar ambos conceptos: identidad y persona. La identidad habla de lo que uno es y de lo que uno aspira a ser. Otro término muy utilizado es el de personalidad, como el contenido propio de la identidad. Tampoco la identidad es algo cerrado o una meta por descubrir, sino más bien la entendemos como un proceso cambiante.
Precisamente nuestra época ha sido denominada posmodernidad; un momento donde tras la pérdida de la verdad como objeto de conocimiento, llegamos a la crisis. Se trata de la negación de la realidad en el proceso interminable de la interpretación. Todo se hallaría en una constante versión beta. Hay, en palabras de J. Ballesteros (1989: 86) una "disolución de lo consciente en lo inconsciente y la negación de la persona en un indefinido número de máscaras”. La fragmentación y la disolución del yo en la "modernidad líquida” chocan decididamente con la intención del adolescente de imponer su ego en la red social. Zygmunt Bauman sostiene que la nueva importancia que se concede a la identidad es un reflejo del hecho de que se está convirtiendo cada vez más problemática la globalización, la disminución del estado de bienestar, aumento de la movilidad social, una mayor flexibilidad en el empleo, inseguridad en las relaciones personales, todos estos acontecimientos están contribuyendo a un sentido de fragmentación y la incertidumbre, en el que los recursos tradicionales para la formación de la identidad ya no son tan sencillos o tan fácilmente disponibles.

El yo tiene muchas caras, donde se refleja lo que desearían ser y esto se va transformando continuamente, porque de alguna manera decimos que no tienen una personalidad formada. Sirven a nuestra exposición las nociones contemporáneas de hombre como "ser en construcción”, como algo dinámico, en permanente cambio. El adolescente ya es una persona y al mismo tiempo está en construcción, en "la manifestación paradójica del yo en la sociedad informacional” (Castells, 2005: 51). Se trata al fin de un "yo posmoderno", que se construye y manifiesta en sus distintas dimensiones, las cuales narra en su entorno digital, como puede verse en la figura 1. Los estereotipos y roles elegidos -o en los que el usuario queda asociado -tienen que ver con el lenguaje en el que se expresa -icónico o verbal-, el mundo compartido a través de los objetos digitales, las ideas y gustos que expresa o las causas que lo comprometen o promueve. Si bien son sus relaciones digitales con objetos y personas las que marcan un universo identitario al que cualquier internauta pertenece. Son perfiles, comentarios, imágenes y pequeños manifiestos a modo de grafitis virtuales los que ayudan a construir el yo juvenil en una red de muchos otros jóvenes. 


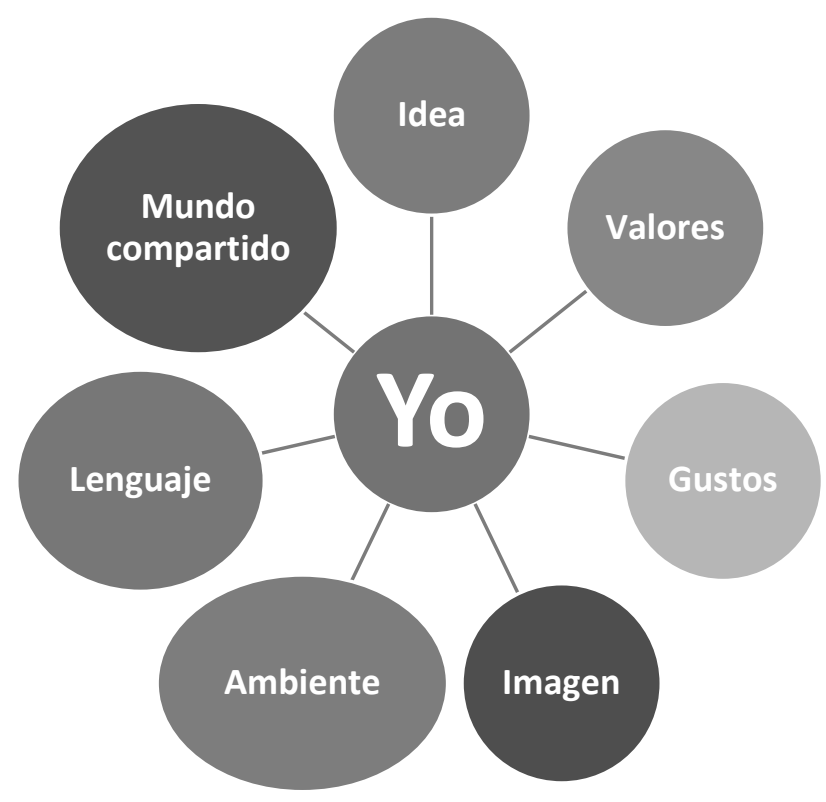

Figura 1. Manifestaciones del yo narrativo en el entorno digital. Fuente: elaboración propia

La persona vive en un proceso constante de identificación, que en esta etapa vital de la adolescencia pasa a un primer plano. Se trata de una búsqueda dubitativa e incluso inconsciente, donde la persona narra un relato que sea coherente para él mismo. Quiere saberse único y protagonista de una historia que comparte en relaciones de intimidad. Ahora bien, esta identidad no es sólo la historia que nos contada. Las personas parecen tener múltiples dimensiones de sus identidades, y es posible que se resistan a tener que seleccionar una que anula todas las demás. Hemos de tener cuidado con esta cuestión, pues se pueden reforzar unos estereotipos por oposición a otros y, por tanto, como negación de otras identidades.

\section{Identidad personal y colectiva}

El adolescente se sabe un "yo" y un "nosotros”, que comienza a explotar fuera del círculo familiar, en las relaciones de amistad. Tiene conciencia de su pertenencia a un grupo y es quizá este el rasgo más sobresaliente que ofrece la integración en una red social virtual. La red social se presentará así como una oportunidad de reafirmación de su “yo" y su "nosotros". La identidad individual está al servicio de un molde social. Esa identidad que el adolescente busca a toda costa como algo irrepetible y, al mismo tiempo, establece dentro de un proceso de identificación en el “nosotros”, le llevará al reconocimiento por los demás, lo que precisamente reafirma su yo. Veremos, pues, rasgos identitarios del adolescente en su pantalla social. Se trata, como afirma Buckingham (2008: 7) de "un concepto resbaladizo, que implica similitud y diferencia. Algo en sí y algo en relación a otros”. Aquí radica la dificultad del concepto: lo que soy (o que creo que soy) varía en función de con quién estoy, lo social, las situaciones en las que me encuentro y las motivaciones que pueda tener en ese momento.

\section{Enfoques sobre la identidad}

Podemos agrupar los enfoques sobre la identidad desde distintas disciplinas. El enfoque psicológico se centra en la adolescencia como una "crisis hormonal" o bien, como una etapa dentro del desarrollo evolutivo en transición desde la niñez a la juventud. Los estudios sociológicos se centran en los factores de desigualdad propios de la edad como son la clase social, el género, el origen, etc. Factores estos que son aprovechados por el marketing, para diseñar productos de consumo relacionados con el perfil identitario de adolescente. Estos productos digitales, como pueden ser las redes sociales, también proporcionan medios para la rebelión o contestación adulta.

La sociología, la psicología social y la antropología tratan la cuestión como un proceso social, no fijo, sino en permanente cambio. Destaca la importancia de las relaciones entre el individuo y el grupo: cómo la gente categoriza o se etiqueta a sí mismo y a otros, cómo se identifican, etc. Los medios se convierten en un instrumento identitario poderoso, que puede hacer relativa la identidad para mostrar lo inhibido o para engañar. El yo se convierte en una especie de "proyecto" que los individuos tienen que trabajar: tienen que crear "narrativas autobiográficas" donde se explican a sí mismos, y mantener por tanto un relato coherente y consistente. Esto es visto por Foucault como simplemente otro modo de ejercer la disciplina del poder. Foucault sostiene que lo que somos -o que nos percibimos ser- está lejos de ser un asunto de elección personal, por el contrario, es el producto de una forma poderosa y sutil de "gubernamentalidad" característica de las democracias modernas (Boyd, 2008: 3).

Abordaremos aquí diferentes perspectivas teóricas para la comprensión de los adolescentes y los medios digitales (Buckingham, 2008: 4). La perspectiva "psico-biológica” de Hall presenta la adolescencia como la tormenta perfecta. La teoría del desarrollo entiende la adolescencia como una de las etapas con su propia crisis, que en este caso sería la identidad y la aplicación de roles. El cuestionamiento de los ideales y valores, una suerte de revisión casi total de la existencia. A través de este proceso de la autorreflexión y autodefinición, los adolescentes llegan a un conocimiento integrado y coherente de su identidad como algo que persiste en el tiempo. La familia y el grupo son determinantes en este desarrollo. Un período de "crisis de identidad", donde la inserción en un conjunto de jóvenes con características homogéneas es condición de supervivencia social en la sociedad contemporánea. Erikson y sus seguidores afirman que las etapas son universales, aunque se podría argumentar que "la adolescencia" como tal no existe en periodos históricos anteriores, o en otras culturas o sociedades. La "adolescencia" es esencialmente un construir histórico y social, en lugar de un estado universal del ser. La adolescencia se ve principalmente como un estado de transición, un asunto de "convertirse" en lugar de "ser". Sus experiencias actuales sólo tienen importancia en la medida en que les ayudan a resolver su crisis y por lo tanto seguir adelante. En los análisis sociológicos la persona joven es un receptor pasivo de las 
influencias de adultos, un "devenir" en lugar de un "ser" por derecho propio. A menudo implican una visión patológica de los jóvenes constituidos en un "problema social" o "en riesgo".

Otra perspectiva teórica sobre el concepto es la que nos ofrece la antropología. La identidad entendida también como algo personal. Lo que es útil a nuestro estudio es la noción de persona como sujeto individual. Y esto es necesario destacarlo, pues trataremos a las personas-adolescentes como grupo, pero no queremos perder de vista la individualidad, como centro de libertad, que afirma la íntima libertad inherente al sujeto, que lo define y le trasciende. La condición personal es señal de unicidad e irrepetibilidad. El ser personal puede reconocerse a sí mismo por su capacidad de autorreflexión. Las notas características del ser persona, junto con la intimidad y la manifestación corporal o el diálogo permiten estudiar al joven usuario desde diferentes ángulos: su aspecto físico, psicológico, social y cultural. Las imágenes (en general, fotografías) dan cuenta de la vestimenta y la apariencia física que los adolescentes desean mostrar como símbolo de una actitud. Lo mismo ocurre con el lenguaje que utilizan y los textos que les representan en la red o comparten: son señales inequívocas de un estilo de vida.

\section{Relaciones virtuales: lo público, lo privado y lo íntimo}

Para tratar adecuadamente la identidad personal hemos de acercarnos al interior de la persona. Para llegar a atisbar un autoconocimiento tal es necesario poseer cierta madurez y la adolescencia no es sino el momento donde se da un crecimiento cualitativo: el nacimiento de la intimidad. Esta se caracteriza por la autoconciencia de la riqueza interior en su propia contradicción interna (por ejemplo, pensemos en el contraste entre la pasión por la soledad y la necesidad del grupo). El yo se marca como la diferencia con lo que le rodea. La búsqueda de la intimidad es uno de los problemas del adolescente. Busca saber quién es para poder diferenciarse y afirmarse como único.

Tales de Mileto en su famoso "Nosce te ipsum" animaba a los jóvenes a conocerse, a entrar en su zona reservada. Así, para algunas personas, el conocimiento de lo interior, de lo íntimo, aparece vinculado con la amistad. Es precisamente este fenómeno uno de los más llamativos en las redes sociales, como los adolescentes se muestran a sus amigos y comparten su intimidad. Pero ¿a qué temas se refiere esta intimidad? Hemos referido ya de forma general todo lo que se considera "interior": el mundo afectivo, la expresión corporal, las ilusiones, metas o proyectos, los estados de ánimo, el sentido de la vida, la situación familiar, etc.

La intimidad se ha visto ligada en numerosas ocasiones al pudor o la vergüenza, que lleva a perder el famoso sentido del ridículo en compañía de los amigos, a proteger lo que escribimos y a requerir confianza para manifestar lo que en realidad pensamos. La esfera de lo privado choca por completo con lo público en la red: he aquí una de las perplejidades que se obtienen en este estudio. Se trata de relaciones privadas de una forma semipública, con una manifestación de la intimidad exteriorizada. La novedad de contar siempre algo en la red sobre uno mismo manifiesta un deseo constante de darse a conocer, también en lo íntimo y, asimismo, un anhelo imperioso por conocerse realmente en la relación con el otro.

Internet ofrece importantes oportunidades para explorar las facetas de los estilos de vida que anteriormente podrían haber sido negadas o estigmatizadas. Los medios de comunicación se pueden utilizar como un medio para expresar o incluso descubrir aspectos de su "verdadero yo", por ejemplo, la relación (Buckingham, 2008: 8). Precisamente la red social es una herramienta para crear y reforzar las relaciones personales, utilizando para ello el exhibicionismo de la intimidad propia y ajena. Responde esto a las necesidades de los adolescentes de obtener un espacio de intimidad y un ámbito exclusivo lejos de sus padres y otros adultos. Tello (2013: 208) menciona el concepto lacaniano de "extimidad" referido a las redes sociales y señala con preocupación la erosión de la intimidad por tres causas: la tecnología permisiva para el seguimiento de la vida de las personas, la búsqueda de beneficios y falta de control de los gobiernos. El exhibicionismo es un desbordamiento de lo íntimo, pero la difusión de las imágenes de terceros también es un problema acuciante. Estos asuntos permiten cuestionarse dónde está la raíz del problema: ¿en publicar lo íntimo o en difundir lo público?.

Sin embargo, por otra parte, estos medios de comunicación también pueden proporcionar potentes oportunidades para el juego de la identidad y de la parodia. Aquí, el énfasis no se encuentra en la honestidad y la verdad, sino en el potencial de rendimiento e incluso para el engaño. Las mediaciones tecnológicas amplifican la visibilidad de lo privado y también de lo íntimo. Boyd (2008: 125) señala características de las redes sociales que aclaran este panorama: la persistencia y la replicabilidad. El hecho de que internet sea la memoria más grande del mundo afecta decisivamente a la identidad e intimidad de las personas y aún quedaría de manifiesto algo que desborda nuestro trabajo: el derecho a la intimidad. La intimidad queda expuesta a miles de contactos y existe la posibilidad de rehacer esa autonarrativa por la capacidad de réplica en los comentarios de las fotografías, etc. La cultura de la transparencia rechaza el anonimato acusándolo de falta de personalidad y exige sobremanera deliberadas acciones educativas, para incidir sobre una auténtica identidad digital.

Hemos visto qué es la persona y cuáles son sus notas características. Tanto el lenguaje como la intimidad nos hablan de una oposición entre el yo y el otro. "El conocimiento de la propia identidad, la conciencia de uno mismo, sólo se alcanza mediante la intersubjetividad” (Taylor, 1994) Estas relaciones pueden ser públicas o privadas, pero siempre han de poseer cierta interactividad. Queda pendiente aún por definir de qué tipo serán las relaciones en la red, donde se observan diferentes niveles de relación, en su mayoría semipúblicas o semiprivadas. El mundo digital permite esos conjuntos de relaciones que existen en la realidad. Las relaciones virtuales de amistad suponen un sistema 
de apoyo moral y emocional, también social. La comunicación y la relación son las principales finales en el uso de sus redes sociales (Bringué y Sádaba, 2011: 88). El tener ciertos contactos habla de uno mismo: los considerados mejores mejoran mi imagen, por su belleza o atractivo, por su prestigio, por su autenticidad, etc. Interesa hacer aquí una breve mención a la tendencia dominante hoy en educación a condenar todo lo virtual confundiéndolo con lo ficticio e incluso lo engañoso. Lo virtual se llama así en cuanto la herramienta de comunicación que utiliza, pero no es menos verdadero y real. Las ciberrelaciones son un fenómeno real, que encadenan las identidades que representan. No siempre se circunscriben a lo verdadero, pero ocupan un amplio espacio del yo que desea y proyecta una imagen, un anhelo de ser alguien.

El acercamiento a la generación interactiva se está abordando desde distintas perspectivas, quizá en la mayoría de los casos desde la prevención ante los riesgos. Pensamos que también deben identificarse nuevos aspectos del uso de las tecnologías en la propia construcción personal de los nativos digitales. No sólo actúan y se combinan con estas, sino que es indudable el lugar que ocupa la familia y la escuela en la formación de la personalidad, aunque muchos de ellos sean inmigrantes digitales.

\section{Conclusiones}

Los adolescentes son a la vez idealizados y demonizados, los adultos les tienen miedo, pero su objetivo es también protegerles (Boyd, 2008: 56). Protegerles marcando espacios separados, con una clara barrera cultural sociológica entre adultos y adolescentes. Necesitamos reconocer cómo fuerzas comerciales crean oportunidades y ponen límites a los jóvenes digitales y que el acceso a estos medios y las formas en que son utilizados en parte dependen de las diferencias que tienen que ver con factores como la clase social, el género y el origen étnico. Sin embargo, por otro lado, también tenemos que considerar cómo estos medios de comunicación proporcionan a los jóvenes recursos simbólicos para construir o expresar sus propios estilos de vida.

La formación de la identidad implica a menudo un proceso de estereotipos. Los adultos ya no son maestros de identidad Los usos interactivos de los jóvenes a través de las tecnologías pueden servir como un modelo para los procesos de identidad (Weber y Mitchell, 2008: 32). Profundizar en la identidad digital de los adolescentes en el propio medio es necesario para abordar con eficacia los fenómenos juveniles emergentes (brechas sociales, riesgos, movilización social, etc.) desde el ámbito educativo.

Los educadores no solo habrían de formarse técnicamente en las novedades digitales y las distintas herramientas, sino más bien comprender las redes y las aplicaciones digitales desde su propia dinámica de funcionamiento. Puede un adolescente estar fuera de estos sitios virtuales, pero no sin una alta factura en cuanto su integración con sus iguales. Al mismo tiempo, bajo la excusa de "estar donde todos están” no cabe la inhibición de los adultos ante los sitios juveniles y el cómo afectan a cada persona. Es tarea urgente la educación digital de fondo y no solo de forma, donde se procure la coherencia en los estilos de vida saludables y respetuosos con la diversidad. La forja de la personalidad de un adolescente, ahora más que nunca, se juega en un teclado y una pantalla, verdaderos espejos del juego, la imitación, el carnaval. A veces, se trata de la tragedia de una autoestima en construcción, que busca el reconocimiento del otro desesperadamente. Además de esos otros sus iguales, potenciales identidades cambiantes, son los educadores (familias y profesorado) líneas del marco que los refleja. La autenticidad y aun el compromiso solidario en causas sociales, tales como la acción política o el apoyo a iniciativas sociales se combinan adecuadamente con un delicado respeto por cada persona, por su honor e intimidad, y se constituyen en posibles fuentes de crecimiento personal.

\section{Referencias}

Ballesteros, J. (1989). Postmodernidad. Madrid: Tecnos.

Bauman, Z. (2003). Modernidad líquida, Mexico: Fondo de cultura económica.

Boyd, D. (2007). Why Youth (Heart) Social Network Sites: The Role of Networked Publics in Teenage Social Life. MacArthur Foundation Series on Digital Learning Youth, Identity, and Digital Media Volume (ed. David Buckingham). Cambridge, MA: MIT Press. Disponible en: http://www.danah.org/papers/WhyYouthHeart.pdf

Bringué, X. y Sádaba, C. (2011). Menores y redes sociales, Madrid: Foro Generaciones Interactivas.

Buckingham, D. (2008). Introducing Identity, Institute of Education, University of London, Centre for the Study of Children, Youth and Media.

Castells, M. (2005). La era de la información: economía, sociedad y cultura. Madrid: Alianza, Vol. I: La sociedad red.

Jenkins, R. (2008). Social identity, New York: Routledge.

Oliveira, Maria Claudia Santos Lopes de. Identidad, narrativa y desarrollo en la adolescencia: una revisión crítica. Psicol. estud. [online]. 2006, vol.11, n.2, pp. 427-436.

Pindado, J. (2006). Los medios de comunicación y la construcción de la identidad adolescente. Zer: Revista de estudios de comunicación, 21, 9-20.

Sanders, T. (2005). The likeability factor. New York: Random House.

Taylor, C. (1994). Ética de la autenticidad. Barcelona: Paidós.

Tello, L. (2013). "Intimidad y "extimidad” en las redes sociales. Las demarcaciones éticas de Facebook”. Revista Comunicar, vol 41: Agujeros negros de la comunicación 